Vol.3 No.1 Hal. $32-38$

Juni 2020

\title{
Analisis Perbandingan Teknologi Pendidikan Anak Berkebutuhan Khusus di Negara Indonesia dan Negara-Negara Eropa (Finlandia, Jerman, Inggris, Belanda)
}

\author{
${ }^{(1)}$ Ulwa Humairok GL, ${ }^{(2)}$ Herry Widyastono \\ Pendidikan Luar Biasa Universitas Sebelas Maret Surakarta ${ }^{(1)(2)}$ \\ Ulwahumairok@gmail.com, herrywidyastono@staff.uns.ac.id
}

\begin{abstract}
ABSTRAK
Teknologi merupakan penerapan pengetahuan yang ilmiah, dan tertata. Teknologi merupakan suatu proses atau cara berfikir bukan hanya produk seperti komputer, satelit,dan sebagainya. Tujuan dari penelitian ini adalah untuk mengetahui peran teknologi pendidikan di Indonesia dan negara-negara Eropa (Finlandia, Jerman,Inggris, Belanda), dalam membantu melaksanakan pendidikan baik formal di sekolah sekolah maupun non formal. Teknologi pendidikan merupakan proses yang komplek dan terpadu untuk menganalisis serta memecahkan masalah belajar atau pendidikan manusia utamanya anak berkebutuhan khusus. Metode penelitian yang akan digunakan adalah metode literatur, yaitu pengumpulana data dari buku pustaka, kemudia dicari data dari paper yang mendukung. Setelah itu data yang terkumpul di analisa, sehingga dihasilkan kesimpulan. Data sekunder diperoleh dari buku pustaka yang mendasari teknologi pendidikan anak luar biasa. Data primer diperoleh dari paper atau jurnal yang ada di situs-situsresmi di internet. Data yang sudah terkumpul disusun kemudia dianalisis, sehingga diperoleh suatu kesimpulan yang sesuai. Kesimpulannya setiap negaranegara di Indonesia dan Negara-negara Eropa memiliki teknologi pendidikan untuk anak berkebutuhan khusus yang berbeda- beda dan beragam yang fungsinya untuk membantu mempermudah akses anak berkebutuhan khusus untuk memecahkan masalah belajar dalam memperoleh pendidikan.
\end{abstract}

Kata Kunci : Teknologi, Pendidikan, Anak Berkebutuhan khusus

\begin{abstract}
Technology is the application of scientific knowledge, and ordered. Technology is a process or way of thinking not just products such as computers, satellites, and so on. The purpose of this study is to determine the role of educational technology in Indonesia and European countries (Finland, Germany, the United Kingdom, the Netherlands), in helping carry out both formal education in schools and non-formal schools. Educational technology is a complex and integrated process for analyzing and solving learning or human education problems, especially children with special needs. The research method that will be used is the literary method, which is the collection of data from literature, then look for data from supporting papers. After that the data collected is analyzed, so conclusions are generated. Secondary data were obtained from literature that underlies the technology of extraordinary children's education. Primary data were obtained from papers or journals available on official websites on the internet. The collected data was compiled then analyzed, so that an appropriate conclusion was obtained. In conclusion, every country in Indonesia and European countries have educational technology for children with special needs who are different and diverse whose function is to help facilitate the access of children with special needs to solve learning problems in obtaining education
\end{abstract}

Keywords : Technology, Education, Children with Special Needs 
Humairok GL, U, Widyastono H: Analisis Perbandingan Teknologi Pendidikan Anak Berkebutuhan Khusus di Negara Indonesia dan Negara-Negara Eropa (Finlandia, Jerman, Inggris, Belanda)

\section{PENDAHULUAN}

\section{Latar Belakang}

Teknologi pendidikan merupakan suatu proses yang komplek dan terpadu melibatkan orang, prosedur, ide, peralatan dan organisasi untuk menganalisis masalah, mencari jalan pemecahan, melaksanakan, mengevaluasi dan mengelola pemecahan masalah yang menyangkut semua aspek belajar manusia. Pemecahan masalah merupakan semua sumber belajar yang didesain, dipilih dan digunakan untuk keperluan belajar. Sumber-sumber belajar terdiri dari pesan, orang, bahan,peralatan, teknik dan latar yaitu lingkungan. Teknologi merupaka cara bagaimana agar pendidikan yang dibangun dan dikelola dapat berdaya guna dan berhasil guna. Sementara pendidikan sebagai suatu produk budaya bangsa untuk mengembangkan kemampuan dan membentuk watak serta peradapan bangsa yang bermartabat dalam rangka mengembangkan potensi peserta didik agar menjadi manusia yang beriman dan bertaqwa kepada Tuhan Yang Maha Esa, berakhlak mulia, sehat, berilmu, cakap kreatif, mandiri dan menjadi warga negara yang demokratis serta bertanggung jawab. Upaya peningkatan kualitas pendidikan di Indonesia dan negara-negara Eropa (Finlandia, Jerman,Inggris, dan Belanda) tidak pernah berhenti. Berbagai terobosan baru terus dilakukan oleh pemerintah melalui Direktorat Pembinaan Guru Pendidikan Menengah dan Pendidikan Khusus. Upaya itu antara lain dalam pengelolaan sekolah, peningkatan sumber daya tenaga pendidikan, pengembangan / penulisan materi ajar, pengembangan paradigma baru dengan metodelogi pengajaran, serta peningkatan teknologi untuk mendukung proses belajar siswa. Pada tahun 1994, pendidikan khusus di Finlandia mengikuti Salamanca Statement (UNESCO) tentang ide inklusif yang diwujudkan dalam kurikulum dan pendidikan di kelas reguler dengan siswa berkesulitan belajar atau dengan kondisi kesehatan yang berat (Finish National Board of Education). Hal ini ditindaklanjuti dengan penetapan The National Core Curriculum Finlandia (2010) menyebutkan bahwa anak berkebutuhan secara utuh tetap bisa dijalankan di ruang sumber dan Basic Education ACT no. 642 (2010) yang menyebutkan bahwa anak berkebutuhan khusus di Finlandia harus menempuh pendidikan di sekolah yang jaraknya terdekat dari rumah. Guru merupakan salah satu faktor yang cukup berpengarus langsung dalam peningkatan mutu tersebut. Guru merupakan jabatan yang paling dipilih berdasarkan prinsip-prinsip vokasional, dalam hal aspek psikologis menjadi faktor untuk melaksanakan tugas dan tanggung jawabnya sebagai pendidik (Oemar Hamalik, 2002 : 24). Peningkatan mutu pendidikan perlu perubahan pola fikir posistif yang digunakan sebagai landasan pelaksanaan kurikulum, serta peningkatan teknologi.

\section{Perumusan Masalah}

Pendidikan anak berkebutuhan khusus pada hakekatnya berbeda dengan pendidikan untuk anak-anak normal, karena pendidikan bagi anak berkebutuhan khusus disamping memberikan pendidikan melalui materi pokok dalam setiap mata pelajaran, juga memberikan pendidikan dalam bentuk layanan pendidikan khusus. Untuk mendukung proses belajar yang efektif dan efisien dibutuhkan media teknologi yang beragam sesuai dengan kebutuhan masing-masing ketunaan

\section{Tujuan Penelitian}

Pengembangan dan pengorganisasian pendidikan khusus di Jerman diselaraskan dengan beberapa resolusi yang diadopsi oleh Standing Conference dan terutama oleh Rekomendasi tentang Organisasi Sekolah Khusus dan rekomendasi untuk pendidikan khusus. Rekomendasi Pendidikan Kebutuhan Khusus di Sekolah-sekolah Republik Federal Jerman dalam beberapa tahunterakhir telah memprakarsai perkembangan penting yang bertujuan untuk membongkar hambatan dan mempromosikan partisipasi setara dari orang muda 
Humairok GL, U, Widyastono H: Analisis Perbandingan Teknologi Pendidikan Anak Berkebutuhan Khusus di Negara Indonesia dan Negara-Negara Eropa (Finlandia, Jerman, Inggris, Belanda)

penyandang cacat dalam pendidikan. Adapun upaya yang ditempuh oleh negara Jerman telah mencakup keseluruhan sistem meliputi usaha menciptakan sekolah yang inklusif bagi anakanak berkebutuhan khusus yang dimulai secara bertahap dengan menerapkan sistem sekolah dengan basis yang beragam dan menyediakan segala fasilitas yang menunjang keberhasilan siswa dalam belajar

\section{METODE PENELITIAN}

Pada penelitian ini, peneliti menggunakan metode penelitian kualitatif deskriptif. Tujuan dari metode penelitian ini untuk menggambarkan bagaimana peran teknologi dalam mendukung proses pendidikandi negara Indonesia dan negara-negara Eropa (Finlandia, Jerman,Inggris, dan Belanda). Metode penelitian yang akan digunakan adalah metode literatur, yaitu pengumpulana data dari buku pustaka, kemudia dicari data dari paper yang mendukung. Setelah itu data yang terkumpul di analisa, sehingga dihasilkan kesimpulan. Data sekunder diperoleh dari buku pustaka yang mendasari teknologi pendidikan anak luar biasa. Data primer diperoleh dari paper atau jurnal yang ada di situs-situs resmi di internet. Data yang sudah terkumpul disusun kemudia dianalisis, sehingga diperoleh suatu kesimpulan yang sesuai.

\section{HASIL DAN PEMBAHASAN}

\section{A. Pemanfaatan Teknologi Anak Berkebutuhan Khusus di Negara Indonesia}

Di Indonesia disabilitas terbagi menjadi beberapa ketunaan. Tunanetra untuk yang mengalami hambatan penglihatan. Tunarungu untuk orang yang mengalami hambatan pendengaran. Tunadaksa untuk difabel yang mengalami hambatan fisik. Tunagrahita untuk anak yang mengalami hambatan intelektual. Serta auitis yang mengalami hambatan perilaku.

Teknologi berperan penting bagi anak berkebutuhan khusus di Indonesia. Dengan adanya teknologi anak berkebutuhan khusus dapat mengikuti perkembangan pendidikan dan pembelajaran di Indonesia. Teknologi yang tercipta dan sesuai mendukung anak berkebutuhan khusus untuk mobilitas dan media belajar yang efektif dan efisien. Sehingga tujuan pendidikan dapat berjalan sesuai kurikulum yang disampaikan oleh pemerintah.

Alat bantu atau media dalam membantu Anak Berkebutuhan Khusus sering disebut dengan Teknologi Asistif (Assistive Technology) yaitu teknologi-teknologi atau segala macam alat/benda yang dengan cara dimodifikasi atau langsung digunakan untuk meningkatkan kemampuan Anak Berkebutuhan Khusus. LiSan merupakan aplikasi komputer untuk penyandang disabilitas daksa dimana sistem kerjanya menggunakan sensor suara. Sedangkan SIDoBi merupakan aplikasi untuk disabilitas rungu dimana sistem kerjanya adalah mentranskrip suara dari video menjadi tulisan pada layar ataupun JAWS yang merupakan sebuah pembaca layar (screen reader) sebuah piranti lunak yang berfungsi untuk mengubah teks menjadi audio pada komputer yang bermanfaat untuk membantu anak disabilitas netra, Computerized Gait Trainers dapat membantu individu/siswa dengan keseimbangan yang buruk atau mereka yang memiliki pengendalian tubuh yang kurang untuk belajar berjalan.

Secara etimologi aksesibilitas bagi penyandang tunanetra berarti kemudahan yang diberikan kepada para penyandang tunanetra, berupa pengadaan atau modifikasi sarana dan prasarana kehidupan sehari-hari, termasuk lingkungan fisik, yang disesuaikan dengan kondisi dan kebutuhan penyandang tunanetra, agar mereka dapat melakukan aktivitas sehari-hari secara mandiri. Dalam desain bangunan dan lingkungan berdasarkan rancangan universal bagi 
Humairok GL, U, Widyastono H: Analisis Perbandingan Teknologi Pendidikan Anak Berkebutuhan Khusus di Negara Indonesia dan Negara-Negara Eropa (Finlandia, Jerman, Inggris, Belanda)

penyandang tunanetra meliputi: pencahayaan (baik secara alami ataupun buatan), ukuran huruf pada petunjuk, huruf timbul pada petunjuk, braile pada petunjuk, informasi yang bisa diraba pada pegangan/handrails tangga, informasi yang bisa diraba pada pegangan/handrails di koridor, informasi yang bisa diraba pada pintu, informasi yang bisa diraba pada permukaan lantai, informasi suara dan petunjuk, informasi penciuman dengan penanaman tumbuhan, area sirkulasi yang tertata, permukaan lantai dan dekorasi dinding tidak membingungkan penglihatan. Fasilitas Laptop dimana dalam kybordnya terdapat tanda garis pada huruf " $F$ " dan "J", memudahkan tunanetra untuk menggunakan Laptop. Adanya Scanner memudahkan tunanetra membaca file atau literasi berupa buku dan majalah berbentuk hardcopy. Tunarungu Memanfaatkan google translate yang telah tersedia di laptop siswa tuli dikoneksikan dengan mic dengan jaringan Bluetooth, sehingga produk suara guru dapat diubah menjadi teks pada layar monitor siswa tuli

\section{B. Pemanfaatan Teknologi Anak Berkebutuhan Khusus di Negara Finlandia.}

Pada "National Plan for Educational Use of Information and Communicton Tchnology" tahun 2010 mencantumkan prinsip penggunaan teknologi dalam lingkup pembelajaran diantaranya meningkatkan interaksi guru dengan siswa, menyesuaikan pembelajaran dengan gaya belajar individual, memberikan timbal balik, mendukung pembelajaran metakognitif, meningkatkan kolaborasi siswa maupun guru, serta meingkatkan produktivitas kegiatan administrasi pendidikan.

Finlandia merupakan sebuah negara skandinavia. Telephone genggam nokia berasal dari negara ini. Finlandia adalah negara di eropa utara dan anggota dari uni eropa. Finlandia juga merupakan walfare state yang berarti pajak yang besar bagi setiap orang. Sebagai gantinya, kesejahteraan yang cukup terjamin disana. Pemerintah Finlandia membentuk sistem pendidikan yang fleksibel dengan prinsip sedikit mengajar, perbanyak belajar.Hal tersebut menjadikan pendidikan di negara Finlandia mencetak lulusan-lulusan yang berkualitas dan memiliki daya saing yang tinggi.Salah satu lulusan dari Finlandia yang terkenal adalah Linus Torvalds sebagai perekayasa software karena menciptakan sistem operasi open-source kernel Linux.

Pemanfaatan teknologi juga diterapkan di ranah pendidikan khusus. Karrna- Iin Bednarik, Sutinen,\& Virnes (2007) menyebutknan empat teknologi yang digunakan untuk anak berkebutuhan khusus di Finlandia, yakni:

1. Assistive technologies : alat yang bisa meningkatkan kapasitas kemandirian dan inisiatif anak berkebutuhan khusus. Ragamnya dari walking sticks, magnifying glasses to speech synthesizes, dan high developed computer systems.

2. Communication devices, terbagi menjadi perangkat tradisional dan perangkat teknologi. Perangkat tradisional meliputi augmentative and alternative communication, dan simple boards, sementara perangkat teknologi meliputi electronic speech devices and computer based communication programs.

3. Learning software, banyak digunakan oleh anak berkesulitan belajar spesifik. Programnya berwujud computerized drills, intelligent tutoring. Merek yang paling sering digunakan adalah Lexia dan Dyslex untuk pembelajaran membaca menulis dan keterampilan kognitif, sementara untuk pembelajaran matematika dan keterampilan perseptual menggunakan program Cami.

4. Educational Robotics as a Concretizing Tool, digunakan untuk memudahkan anak menyusun maupun memahami konsep dengan membuat model tertentu, bentuknya mirip dengan lego dalam aneka jenis seperti kendaraan, bangunan, dan lain-lain. 
Humairok GL, U, Widyastono H: Analisis Perbandingan Teknologi Pendidikan Anak Berkebutuhan Khusus di Negara Indonesia dan Negara-Negara Eropa (Finlandia, Jerman, Inggris, Belanda)

\section{Teknologi Pendidikan anak Berkebutuhan Khusus di Negara Jerman}

Dalam sebuah laman artikel disebutkan bahwa perkembangan teknologi yang ada untuk penyandang difabel di Jerman sudah sangat maju terdapat fasilitas-fasilitas umum yang sudah memenuhi standar aksesibilitas bagi penyandang disabilitas. Meski tak semua kategori hambatan fisik dapat terakomodasi tetapi hampir semua infrastruktur publik di Jerman menyediakan aksesibilitas bagi penyandang disabilitas. Sarana transportasi umum, misalnya pintu bus atau kereta dibuat lebar dan sejajar halte hal ini memudahkan kursi roda masuk. Didalam kereta terdapat tulisan imbauan untuk mengutamakan tempat duduk bagi penyandang disabilitas dan pemberitahuan suara menjelang setiap pemberhentian kereta.

Selain dari aksesibilitas untuk anak-anak penyandang disabilitas ada beberapa temuan yang dapat membantu proses pembelajaran anak berkebutuhan khusus diantaranya adalah baju pasir. Baju ini didesain untuk dipasangkan kepada anak dengan ADHD. Baju ini didesain agar anak mampu meningkatkan konsentrasi anak karena tidak mampu bergerak secara cepat. Meskipun banyak sekali perdebatan dengan penggunaan baju ini akan tetapi menurut beberapa penelitian baju ini sangat mendukung konsentrasi anak ADHD.

\section{Teknologi Pendidikan Anak Berkebutuhan Khusus di Inggris}

Salah satu teknologi yang dikembangkan guru di Inggris adalah edtech. Dimana ini digunakan untuk menangani anak dengan disleksia dan autisme yang dapat menyesuaikan pelajaran untuk memenuhi kebutuhan siswa. Di depan kelas guru menggunakan ActivPanel, Layar Panel Datar Interaktif atau Interactive Flat Panel Display (IFPD) yang terbukti bermanfaat dalam melibatkan siswa SEN dalam pelajaran. Ada 5 elemen yang menjadi kelebihan dari IFPD ini, yaitu :

1. Latar belakang

Untuk murid disleksia, warna latar belakang dapat membuat dunia berbeda, banyak murid disleksia sering berjuang dengan menafsirkan teks hitam pada latar belakang putih, yang secara default cenderung menjadi format warna standar untuk sebagian besar bahan dan sumber daya. Beberapa murid disleksia sering mengatakan sepertinya surat-surat itu bergerak. Ada aplikasi yang memungkinkan untuk mengubah warna latar belakang sehingga murid disleksia dapat melihat teks lebih jelas. Salah satunya perangkat lunak ActivInspire pada ActivPanel di mana dapat mengubah latar belakang dan warna font dalam banyak sumber daya menjadi apa pun yang diinginkan, atau bahkan menggunakan alat overlay.

2. Templat

Tantangan lain bagi banyak murid disleksia adalah membedakan dan menulis huruf $\mathrm{p}$, b, g dan d. Perangkat lunak ActivInspire atau aplikasi di app store, memberikan akses untuk menarik template dengan tulisan tangan. Murid dapat menggunakan stylus untuk mengikuti spidol dan mengembangkan memori otot pembentukan huruf. Murid bahkan dapat memanipulasi tulisan didalamnya secara fisik dengan jari atau stylus. Keterampilan yang dapat ditransfer ini membuat pembentukan materi jauh lebih mudah ketika kita mengerjakan kegiatan berbasis kertas.

\section{Permainan}

Aplikasi permainan phonic luar biasa untuk membantu siswa mempelajari suara. Aplikasi Play Fonics dapat menjadi alternatif dimana siswa harus menembak suarasuara tertentu dari langit dan setiap kali mereka menekan permainan membuat suara huruf. Mampu membuat hubungan antara huruf-huruf secara visual dan suara melalui aktivitas yang menyenangkan dan menarik sehingga membantu siswa untuk lebih mengingat huruf. 
Humairok GL, U, Widyastono H: Analisis Perbandingan Teknologi Pendidikan Anak Berkebutuhan Khusus di Negara Indonesia dan Negara-Negara Eropa (Finlandia, Jerman, Inggris, Belanda)

4. Konektivitas

Laptop, iPad dan tablet lainnya telah menjadi alat utama dalam pengajaran literasi digital. Mampu menghubungkan semua perangkat ini ke ActivPanel menggunakan perangkat lunak ClassFlow berbasis cloud telah memungkinkan untuk tingkat interaktivitas dan umpan balik.

5. Jadwal

Organisasi dan struktur dalam pelajaran penting untuk setiap murid, tetapi terutama bagi mereka yang memiliki kecenderungan autis atau yang memiliki tantangan dengan ingatan. Mungkin sulit bagi siswa ini untuk tetap terlibat dan dalam tugas. Didalam kelas menggunakan aplikasi yang disebut Jadwal Visual pada ActivPanel, itu sangat bermanfaat bagi siswa SEN untuk merencanakan agenda kelas. Banyak universitasuniversitas di Inggris juga memiliki fasilitas yang memadai bagi kaum disabilitas berupa ruangan yang terbuka dan terdapat guilding block disetiap pendestrian, tersedianya kursi roda bagi mahasiswa yang memiliki kebutuhan khusus dalam bermoblitas. Serta banyaknya fasilitas lain yang dirancang aksesibel bagi penggunanya, baik itu disabilitas maupun mahasiswa reguler.

\section{E. Pemanfaatan Teknologi Anak Berkebutuhan Khusus Negara Belanda}

1. Stasiun Kereta Api

Lebih dar $90 \mathrm{~km}$ telah dipasangi pedoman yang dapat dilihat dan dipahami bagi tunanetra dan low vision. Selain pedoman, navigasi di stasiun telah diatasi dan 800 tanda braille telah diperkenalkan. Ini dapat ditemukan di lift dan tangga dan memberi tahu pembaca tentang platform yang mengarah atau menuju ke jalan. Ubin suara juga telah ditempatkan di stasiun. Mereka menghasilkan suara yang berbeda dengan ubin di sekitarnya ketika diketuk dengan tongkat atau kaki, dan sering menandai persimpangan atau ujung strip pemandu. Anda dapat melihatnya di depan toko-toko layanan dan tiang-tiang check-in. 5.000 deskripsi rute lisan telah ditambahkan ke stasiun dan hambatan telah dihapus dari jalur berjalan. Selain itu, pagar tangga tambahan berada di bawah langkah-langkah yang diambil untuk meningkatkan aksesibilitas bagi para tunanetra. Di stasiun pusat di Amsterdam, Utrecht, Den Haag dan Rotterdam, peta taktil dari stasiun telah dibuat juga.

\section{KESIMPULAN}

Pemanfaatan teknologi pendidikan di Indonesia dengan negara lain tidak jauh berbeda. Pemerintah disetiap negara telah sama-sama memperhatikan teknologi untuk anak berkebutuhan khusus. Pemanfaatan teknologi untuk anak berkebutuhan khusus di Indonesia ataupun negara-negara eropa (Finlandia, Jerman,Inggris, Belanda) hampir semua sama, walaupun terdapat beberapa hal yang berbeda. Setiap Negara masih membutuhkan perbaikan dalam beberapa hal untuk memaksimalkannya. Secara pesat, teknologi ini mengubah cara hidup masyarakat, di mana batas ruang dan waktu sudah tidak menjadi kendala besar (borderless). Bahkan kehadiran google yang sangat fenomenal ini semakin mengukuhkan pendapat bahwa tekonologi informasi dan komunikasi telah menjadi mainstream budaya masyarakat dunia saat ini . Padahal di sisi lain, Informasi media massa (baik media cetak, media elektronik, maupun cybermedia) memiliki pengaruh yang lebih besar dari apapun. 
Humairok GL, U, Widyastono H: Analisis Perbandingan Teknologi Pendidikan Anak Berkebutuhan Khusus di Negara Indonesia dan Negara-Negara Eropa (Finlandia, Jerman, Inggris, Belanda)

\section{DAFTAR PUSTAKA}

Dewi Salma Prawiradilaga, Eveline Siregar. 2004. Mozaik Teknologi Pendidikan. Jakarta: Perpustakaan Nasional.

Fatah Syukur. 2008. Teknologi Pendidikan. Semarang: MediaGrup.

I Gde Wawan Sudhata, I Made Tegeh. 2015. Desain Multimedia Pembelajaran. Yogyakarta: Media Akademi.

Ishak Abdulhak, Deni Darmawan. 2013. Teknologi Pendidikan. Bandung: PT. Remaja Rosdakarya.

Maswan, Khoirul Muslimin. 2017. Teknologi Pendidikan Penerapan Pembelajaran Yang Sistematis. Yogyakarta: Pustaka Pelajar.

Nunuk Suryani, Achmad Setiawan, Aditin Putria. 2018. Media Pembelajaran inovatif dan Pengembangannya. Bandung: PT.Remaja Rosdakarya.

Rusli.2009. Teknologi Komunikasi Informasi dalam Pendidikan. Jakarta: Gaung Persada. 